\title{
Correlations between motor and sensory functions in upper limb chronic hemiparetics after stroke
}

\author{
Thais Botossi Scalha', Erica Miyasaki², \\ Núbia Maria Freire Vieira Lima ${ }^{3}$, Guilherme Borges ${ }^{4}$
}

\begin{abstract}
Objective: Describe the somatosensory function of the affected upper limb of hemiparetic stroke patients and investigate the correlations between measurements of motor and sensory functions in tasks with and without visual deprivation. Method: We applied the Fugl-Meyer Assessment (FMA), Nottingham Sensory Assessment (NSA), and several motor and sensory tests: Paper manipulation (PM), Motor Sequences (MS), Reaching and grasping (RG) Tests Functional (TF), Tactile Discrimination (TD), Weight Discrimination (WD) and Tactile Recognition of Objects (RO). Results: We found moderate correlations between the FMA motor subscale and the tactile sensation score of the NSA. Additionally, the FMA sensitivity was correlated with the NSA total; and performance on the WD test items correlated with the NSA. Conclusion: There was a correlation between the sensory and motor functions of the upper limb in chronic hemiparetic stroke patients. Additionally, there was a greater reliance on visual information to compensate for lost sensory-motor skills. Key words: stroke, paresis, sensation.
\end{abstract}

Correlações entre função motora e sensorial do membro superior de hemiparéticos crônicos pós-acidente vascular encefálico

\section{RESUMO}

Objetivo: Descrever a função somatossensorial do membro superior afetado de hemiparéticos crônicos após acidente vascular encefálico (AVE) e verificar as correlações entre instrumentos de medida da função motora e sensorial em tarefas com e sem privação visual. Método: Aplicados o Protocolo de Desempenho Físico de Fugl-Meyer (FMA), Avaliação Sensorial de Nottingham (ASN), e os testes de: Manipulação de Papel (MP), Sequência Motora (SM), Alcance e Preensão (AP), Testes Funcionais (TF), Discriminação Tátil (DT), Discriminação de Peso (DP) e Reconhecimento Tátil de Objetos (RO). Resultados: Foram encontradas correlações moderadas entre a FMA motora e itens da subescala sensação tátil da ASN; a FMA sensibilidade correlacionou-se a ASN total; e o teste DP se correlacionou com itens da ANS. Conclusão: Houve correlação entre a função sensorial e motora do membro superior em pacientes hemiparéticos crônicos pós- AVE; e maior dependência das informações visuais para compensar a perda sensório-motora. Palavras-chave: acidente cerebral vascular, paresia, sensação.

Stroke is the leading cause of disability in adults in Brazil ${ }^{1}$, and the resulting impairment of motor function can lead to deficits in coordination of movements ${ }^{2}$, specific muscle weakness ${ }^{3}$, abnormal tone ${ }^{4}$, postural adjustments and abnormal synergistic movements ${ }^{5,6}$ as well as lack of mobility between structures escapular waist ${ }^{7}$. In addition to motor disability, 50\% to $85 \%$ of this population also has somatosensory deficits ${ }^{8}$.

The integrity of the somatosensory
Thais Botossi Scalha

Rua dos Bambus 885

13468-120 Americana SP - Brasil

E-mail: thais_scalha@hotmail.com

Received 30 November 2010 Received in final form 8 April 2011 Accepted 15 April 2011
State University of Campinas, Campinas SP, Brazil: ${ }^{1}$ Mastering in Biomedical Sciences; ${ }^{2}$ Physiotherapist Specialist in Neurology Physical Therapy: ${ }^{3}$ Master in Biomedical Sciences, Medical Sciences Faculty; ${ }^{4}$ Professor, Department of Neurology, Medical Sciences Faculty. 
system is important for motor recovery after stroke ${ }^{9}$. Patients with stroke who have sensory and motor impairments have a poorer prognosis than those with motor deficits alone ${ }^{10,11}$. The consequences of the somatosensory deficits include changes in the recognition and manipulation of objects, danger of burns and wounds to the limb, loss of motor control in the affected limb and difficulty in controlling the level of hand strength while reaching ${ }^{12,13}$.

The sensory loss and loss of strength of intrinsic hand muscles are related to the involvement of upper limb movements in hemiparetics ${ }^{14,15}$. The expected recovery of manual control is particularly relevant because the rehabilitation strategy depends on motor recovery and the chance of developing complications secondary to paresis or spasticity ${ }^{16}$. For example, gripping and pinching maneuvers require the identification of the object's properties, including its curvature, size and fragility ${ }^{17}$. Tyson et al. ${ }^{18}$ showed that it is expected that the severity of deficits after a stroke correlates with sensory disturbances, but not necessarily with muscle weakness. The authors mentioned the need for further studies to examine the correlation between sensory and motor deficits after stroke.

There are several instruments to quantitatively and qualitatively profile the deficits in neurological patients after a stroke. These tests are widely used and assist health professionals to assess the level of involvement of sensory-motor functions and functional capabilities. These scales facilitate the definition of the level of sensorimotor recovery and allow the establishment of adequate therapeutic strategies ${ }^{19}$.

Specific functional scales are validated and used in neurorehabilitation clinics in Brazil, such as the Protocol of Physical Performance of Fugl-Meyer ${ }^{20}$ and Sensory Evaluation of Nottingham ${ }^{21}$. When used together, these scales provide an informative projection of the overall performance of the patient. Recent studies have evaluated the description of sensory deficits and analyzed correlations between the scales and the degree of sensory deficits in people with stroke. However, these studies have focused on the acute and subacute stages of recovery ${ }^{17-18,22-25}$. There is scant evidence of a relationship between somatosensory and motor impairment and recovery in chronic hemiparesis.

This objective of this study were, first, to describe the somatosensory function of the affected upper limb of hemiparetic stroke patients and, second, to verify the correlations between instruments measuring motor function with those measuring sensory function, performed in stroke patients with and without visual deprivation.

\section{METHOD}

\section{Study design and participants}

This was a cross-sectional study. The patients were selected according to the following inclusion criteria: both sexes, aged less than 75 years, only a clinical diagnosis of stroke, brain injury time greater than or equal to 2 years, proprioceptive and/or exteroceptive loss in the affected wrist, and ability to comprehend simple instructions. Patients were excluded if they were diagnosed with hemineglect (test of the bells $\mathrm{s}^{26}$ ). Assessments of patients were performed at the Physiotherapy and Occupational Therapy Outpatient Clinic of The Clinics Hospital - UNICAMP. The specific tests have been adapted by the authors from a previous study by Smania et al. ${ }^{13}$. The study was approved by the Ethics Committee of the Medical Sciences Faculty, UNICAMP (No. 420/2009).

\section{Measurement instruments}

Fugl-Meyer Assessment (FMA) - The FMA is an instrument validated in Brazil that measures sensorymotor recovery in stroke patients. The sections related to upper limb motor function and sensibility were applied. The motor section score ranges from 0 to 66, and the score related to exteroceptive and proprioceptive sensitivity ranges from 0 to 12 . The lowest and highest scores correspond to worse and better function, respectivel $y^{20}$. Patients with scores greater than 50 have mild deficits and those with scores less than 50 have moderate to serious deficits ${ }^{27}$.

Nottingham Sensory Assessment (NSA) - This is an instrument validated in Brazil ${ }^{21}$ that evaluates the affected upper limb in the following sensory modalities: tactile sensation (pressure, light touch, temperature, pinprick, tactile location and bilateral simultaneous touch), conscious proprioception, stereognosis and two-point discrimination. The objects offered for the stereognosis test were as follows: coins of $\mathrm{R} \$ 0.01, \mathrm{R} \$ 0.10$ and $\mathrm{R} \$$ 1.00 (real currency), a ballpoint pen, a pencil, a comb, a scissors, a sponge, a piece of flannel fabric, a mug and a cup. Each item of the NSA was graded from 0 (worst function) to 2 (preserved sensation), except for conscious proprioception, which was scored from 0 to 3 points (worst and best function, respectively). The tactile sensation subscale scores ranged from 0 to 24 points and the proprioception subscale ranged from 0 to 6 points (wrist and hand affected).

Paper manipulation (PM) - Each patient was requested to crumple a sheet of paper (A4) with the affected hand into a ball. Patients either received a score of 0 if they were not able to perform the activity or a score of 1 if they were able to perform the activity. The activity was conducted under two conditions: with visual control and blindfolded ${ }^{13}$.

Motor Sequences Test (MS) - The MS measures the patient's performance in four motor sequences using five digits, with alternating movements between the first digit 
and the others: [1] I-II, I-III, I-IV, I-V; [2] I-V, I-IV, I-III, I-II; [3] I-II; I-IV; I-III, I-V; [4] I-III, I-II, I-IV, I-V. Each trial was performed under two conditions: with visual control and blindfolded. One point was assigned for each finger movement performed correctly (maximum score of 4 points $)^{13}$.

Reaching and grasping (RG) - The patients were required to reach and hold a metal cylinder placed in front of them $(20 \mathrm{~cm})$. One point was awarded for successfully being able to perform the activity. The activity was conducted under two conditions: with visual control and blindfolded ${ }^{13}$.

Functional tests (FT) - The composition of seven consecutive tasks was requested by the therapist: [1] closing a zipper; [2] undoing a button; [3] opening and closing Velcro; [4] using a fork; [5] taking a pencil; [6] transferring water from a jug into a glass; and [7] wearing a glove with the aid the affected hand. The tasks were performed in two stages: first, with visual control and, second, blindfolded with supervision. One point was awarded for each task completed. The maximum score was 7 , which was obtained by adding the points together from all the tasks ${ }^{13}$.

Tactile discrimination (TD) - Two blocks of differing spatial structure, 10 and $15 \mathrm{~cm}$ each, were placed under the hands of blindfolded patients (one block in each hand). Tactually, the patient had to explore the surfaces of the blocks and recognize them (greater or minor). The patients were allowed two attempts to describe the shapes. For each correct description, one point was given (maximum score of two points) $^{13}$.

Weight discrimination (WD) - Each patient was asked to lift two objects simultaneously and report whether or not they had equal weights. We used two plastic containers weighing $100 \mathrm{~g}$ and $500 \mathrm{~g}$. The task was performed blindfolded, and patients were given one point for a correct answer ${ }^{13}$.

Tactile recognition of objects (RO) - While blindfolded under supervision, each patient's tactile recognition of seven familiar objects was tested. The objects tested were as follows: [1] a comb; [2] a toothbrush; [3] pencils; [4] a glass; [5] a spoon; [6] a wristwatch; and [7] real currency. One point was given for each task completed. The maximum score was 7 , which was the sum of all tasks ${ }^{13}$.

\section{Procedures}

The patients underwent testing with the instruments described above by a physiotherapist trained and familiar with the scales. The instruments were administered in a single day in the afternoon, and the patients were offered rest periods between tasks to avoid fatigue. When the test required visual deprivation, the patient was blindfolded.
First, the patients were tested on the FMA motor and sensory and NSA scales. Then, PM, MS, RG, and FT tests without visual deprivation were performed. Finally, the tests in which visual deprivation was necessary were performed: TD, WD, RO, PM, MS, RG and FT. All the patients signed an informed consent.

\section{Statistical analysis}

Data measured as continuous variables were described with measures of central tendency and dispersion. Data measured as categorical variables were arranged by frequency. It was not found normal distribution of numerical variables based on the KolmogorovSmirnov test. For the analysis of correlation of the independent variables, we used Spearman's test. To categorize the level of Spearman's correlation coefficient (r), we adopted the following scores: $r<0.40$ corresponded to poor correlation, $r=0.75$ corresponded to moderate correlation, and $r>0.75$ corresponded to high correlation ${ }^{28}$. For analysis of the dependent variables, we used the Wilcoxon test. The level of significance was 5\%. The statistical software used was SPSS 15.0 for Windows.

\section{RESULTS}

Among 50 patients recruited, 20 were included in the study based on the inclusion criteria described above. Table 1 shows the demographic data and scores on the FMA and NSA and its subscales. Table 2 summarizes the distribution of scores for the tests performed with eyes open and closed. Table 3 displays the frequency of scores for the tactile discrimination test, discrimination of weights and tactile recognition of objects.

The FMA sensitivity was correlated with total NSA score ( $p=0.691, p=0.001$ ). We found correlations between the FMA subsection concerning exteroception in the arm with light touch and pressure and the NSA score $(\mathrm{p}<0.005)$. The score on the FMA subsection corresponding exteroception in the palm moderately correlated with all items in the tactile sensation subscale of the NSA $(\mathrm{p}<0.005)$, with the exception of temperature sensation. The score of the FMA section on proprioception (shoulder and elbow) was correlated with the score of the NSA section on proprioception $(r=0.585$, $\mathrm{p}=0.007)$. The latter also correlated with the FMA section on proprioception in the wrist and hand $(r=$ 0.746, $\mathrm{p}<0.001)$.

No correlation was found between the FMA motor score in the wrist and hand and total NSA score. Moderate correlations were found between the FMA motor subscale score and scores on tactile sensation on the NSA. Correlations between the FMA motor score and tactile sensation were as follows: for pressure $r=0.586$ and $\mathrm{p}=0.007$, for temperature $\mathrm{r}=0.613$ and $\mathrm{p}=0.004$, for 
Table 1. Demographic data and scores of rating scales $(n=20)$.

\begin{tabular}{|c|c|c|}
\hline Variables & $\mathrm{n}$ or median & $1^{\circ} \mathrm{Q} ; 3^{\circ} \mathrm{Q}$ \\
\hline $\operatorname{Sex}(F / M)$ & $4 / 16$ & - \\
\hline Age (years) & 52.5 & $35.75 ; 60.5$ \\
\hline Time of stroke (years) & 5 & $2 ; 6.75$ \\
\hline Affected hemisphere (R/L) & $7 / 13$ & - \\
\hline FMA total UL & 26 & $10 ; 44.50$ \\
\hline FMA UL (shoulder and elbow) & 16 & $9.5 ; 19.75$ \\
\hline FMA UL (wrist and hand) & 4 & $1.25 ; 13.75$ \\
\hline FMA total sensitivity UL & 9 & $4.25 ; 10.75$ \\
\hline FMA exteroception arm & 2 & $1 ; 2$ \\
\hline FMA exteroception palm & 1 & $0.25 ; 2$ \\
\hline FMA proprioception (shoulder and elbow) & 4 & $2 ; 4$ \\
\hline FMA proprioception (wrist and thumb) & 2 & $0 ; 3.75$ \\
\hline NSA & 59 & $36.25 ; 75.50$ \\
\hline Light touch & 9 & $4.50 ; 9$ \\
\hline Pressure & 9 & $4.50 ; 12$ \\
\hline Sting & 10 & $7.25 ; 12$ \\
\hline Temperature & 7.5 & $6 ; 9$ \\
\hline Location tactile & 8.5 & $4 ; 11.50$ \\
\hline Bilateral simultaneous touch & 6.5 & $4 ; 9$ \\
\hline Proprioception & 6 & $3 ; 8$ \\
\hline Stereognosis & 1.5 & $0 ; 11.75$ \\
\hline 2-point discrimination & 1 & $0 ; 1$ \\
\hline
\end{tabular}

Table 2. Frequency of test scores $(n=20)$.

\begin{tabular}{lcc}
\hline Instruments to measure (score) & Eyes open & Visual deprivation \\
\hline Paper manipulation (0/1) & $17 / 3$ & $18 / 2$ \\
Motor Sequences test (0/4) & $18 / 2$ & $20 / 0$ \\
Reaching and grasping (0/1) & $13 / 7$ & $14 / 6$ \\
Functional tests $(0 / 1 / 2 / 3 / 4 / 5 / 6 / 7)$ & $11 / 3 / 0 / 2 / 1 / 1 / 2 / 0$ & $10 / 3 / 3 / 1 / 1 / 2 / 0 / 0$ \\
Total score & 51 & $34^{*}$ \\
\hline
\end{tabular}

${ }^{*} p=0.05$ for difference in scores between tests with and without visual deprivation.

touch, bilaterally, $\mathrm{r}=0.518$ and $\mathrm{p}=0.019$, and for proprioception $\mathrm{r}=0.515$ and $\mathrm{p}=0.02$.

We found a correlation between several NSA test items and WD. The correlations were as follows: for pressure and WD, $r=0.627$ and $p=0.003$, for sting and WD $r=0.573$ and $\mathrm{p}=0.08$ and for tactile localization and WD, $r=0.582$ and $p=0.007$. Table 4 shows the Spearman correlation coefficients between FMA motor scores, NSA scores and other tests performed with and without eyes open.

\section{DISCUSSION}

The patients with chronic hemiparesis showed an impairment of all sensory modalities in the affected upper
Table 3. Frequency of test scores $(n=20)$.

\begin{tabular}{lc}
\hline Instruments to measure (score) & Frequency \\
\hline Tactile discrimination $(0 / 1 / 2)$ & $13 / 6 / 1$ \\
Weight discrimination $(0 / 1)$ & $11 / 9$ \\
Tactile recognition of objects $(0 / 1 / 2 / 3 / 4)$ & $13 / 1 / 1 / 3 / 2$ \\
\hline
\end{tabular}

limb and moderate to severe motor impairment. The scores on instruments specific for exteroceptive and proprioceptive sensory function correlated with each other, but no correlation was found between the FMA motor score for the wrist and hand and NSA scores for the same joints. 
Table 4. Spearman correlation coefficients $(n=20)$.

\begin{tabular}{lcc}
\hline Instruments to measure & FMA motor & NSA total \\
\hline PM EO & $r=0.62$ & $r=-0.182$ \\
& $p=0.04$ & $p=0.442$ \\
PM visual deprivation & $r=0.521$ & $r=-0.011$ \\
MS EO & $p=0.019$ & $p=0.627$ \\
& $r=0.521$ & $r=-0.116$ \\
MS visual deprivation & $p=0.019$ & $p=0.627$ \\
RG EO & - & - \\
RG visual deprivation & - & - \\
FT EO & $r=0.774$ & $r=0.191$ \\
& $p<0.001$ & $p=0.42$ \\
FT visual deprivation & $r=0.635$ & $r=0.237$ \\
& $p=0.003$ & $p=0.315$ \\
TD & $r=0.74$ & $r=0.167$ \\
WD & $p<0.001$ & $p=0.482$ \\
RO & $r=0.678$ & $r=0.187$ \\
& $p=0.003$ & $p=0.43$ \\
\hline & $r=0.191$ & $r=0.451$ \\
& $p=0.419$ & $p=0.046$ \\
& $r=0.393$ & $r=0.541$ \\
& $p=0.087$ & $p=0.014$ \\
& $r=0.075$ & $r=0.597$ \\
& $p=0.752$ & $p=0.005$ \\
\hline
\end{tabular}

EO: eyes open; FMA: Full-Meyer assessment; NSA: Nottingham sensory assessment; PM: paper manipulation; MS: Motor sequences test; RG: Reaching and Grasping; FT: functional tests; TD: tactile discrimination; WD: weigh discrimination; RO: tactile recognition of objects.

The sensory and motor functions of the affected upper limb correlated with the functional tests performed with and without visual deprivation. The patients had worse performance with visual deprivation.

Kuijk et al. ${ }^{16}$ evaluated hemiparetics and found that $60 \%$ did not exhibit any upper extremity motor recovery over 26 weeks according to FMA scores. At 6 months after the stroke, $17 \%$ had complete recovery of motor function in the upper extremity and $23 \%$ had partial motor recovery. At 6 months, 12 patients (34\%) developed some function of the hand as evaluated by the hand FMA subscore.

Welmer et al. ${ }^{23}$ evaluated 66 patients at one week post-stroke and reassessed them after 3 months and 18 months. The authors found moderate to strong correlations between hand function and fine sensory testing (light touch and positioning of the thumb) in acute and subacute stroke, but they found only a weak correlation in patients with chronic hemiparesis. One possible explanation for this finding is that learning how to use vision as compensatory mechanism for their sensory deficits may take some time. However, the changes are hardly conscious proprioception compensated by vision and tactile deficits.
Tyson et al. ${ }^{18}$ used the Rivermead Assessment of Somatosensory Perception (RASP), which includes two sensory modalities, light touch and proprioception, and two functional assessments, detection and discrimination of objects. They found a higher deficit in tactile sensation than with proprioception in hemiparetic patients during the acute phase and they found a correlation between these methods, suggesting that measuring these abilities may serve as a tool to quantify sensory recovery.

We found no correlation between motor function and the ability to discriminate weights. Blennerhassett et al. ${ }^{17}$ evaluated fine motor skill (grip) of hemiparetics and found a weak correlation with the ability to discriminate textured surfaces and no correlation with recognition of weights with the thumb and forefinger without the aid of visual cues.

The limitations of this study include the ceiling and soil effect of functional testing due to the small variation of scores among patients, and a small sample size.

These results show a correlation between the sensory abilities and motor function of the upper limb with functional activities in chronic hemiparetic patients after a stroke. This correlation was especially strong in tasks with visual deprivation.

Individuals who suffered from a stroke become more dependent on visual information to compensate for lost sensory-motor information and used visual cues to reorganize the sensory information that changed after the injury. Sensory integration is required to process and organize sensory information for functional use in daily activities and occupational duties. Evidence of this was shown in this article by correlations between the FMA motor subscale and the tactile sensation subscore of the NSA (pressure, temperature, touch, proprioception, and bilateral touch).

The study presents a contribution to the area of neurorehabilitation. However, there is a need for further investigations, particularly a need to compare various instruments used for measuring and analyzing sensorymotor recovery of hemiparetic patients and to determine their use in the planning and implementation of effective rehabilitation programs.

\section{REFERENCES}

1. O'Sullivan SB, Schmitz TJ. Fisioterapia: avaliação e tratamento. São Paulo: Manole, 2004.

2. Trombly C A. Deficit of reaching in subjects with left hemiparesis: a pilot study. Am J Occup Ther 1992;46:887-897.

3. Bourbonnais D, Vanden Noven S. Weakness in patient with hemiparesis. Am J Occup Ther 1989;43:313-319.

4. Wisendanger M. Weakness and upper motoneurone syndrome: a critical pathophysiological appraisal. In: Berardelli A, Benecke R, Manfredi M, Marsden C D (Eds). Motor Disturbances II. London, Academic Press; 1990:319-331.

5. Di Fábio R P, Badke M B, Duncan P W. Adapting human postural reflexes 
following localized cerebrovascular lesion: analysis of bilateral long latency responses. Brain Res 1986;363:257-264.

6. Bobath B. Adult hemiplegia: evaluation and treatment. 3 ed. Oxford, Heinemann Medical, 1990.

7. Ryerson S, Levit K. The shoulder in hemiplegia. In: Donatelli R (Ed). Physical therapy of the shoulder. New York, Churchill Livingstone, 1987:105-131.

8. Kim JS, Choi-Kwon S. Discriminative sensory dysfunction after unilateral stroke. Stroke 1996;27:677-682.

9. Staines WR, Black SE, Graham SJ, Mcllroy WE. Somatosensory gating and recovery from stroke involving the thalamus. Stroke 2002;33:2642-2651.

10. Han L, Law-Gibson D, Reding M. Key neurological impairments influence function-related group outcomes after stroke. Stroke 2002;33:1920-1924.

11. Patel AT, Duncan PW, Lai SM, Studenski S. The relationship between impairments and functional outcomes poststroke. Arch Phys Med Rehabil 2000;81:1357-1363

12. Carey LM, Matyas TA, Oke LE. Evaluation of impaired fingertip texture discrimination and wrist position sense in patients affected by stroke: comparison of clinical and new quantitative. J Hand Ther 2002;15:71-82.

13. Smania N, Montagnana B, Faccioli S, Fiaschi A, Aglioti SM. Rehabilitation of somatic sensation and related deficit of motor control in patients with pure sensory stroke. Arch Phys Med Rehabil 2003;84:1692-1702.

14. Hendricks $H T$, Hageman $G$, van Limbeek J. Prediction of recovery from upper extremity paralysis after stroke by measuring evoked potentials. Scand J Rehabil Med 1997;29:155-159.

15. Kamper DG, Fischer HC, Cruz EG, Rymer WZ. Weakness is the primary contributor to finger impairment in chronic stroke. Arch Phys Med Rehabil 2006;87:1262-1269.

16. Van Kuijk AA, Pasman JW, Hendricks HT, Zwarts MJ, Geurts ACH. Predicting hand motor recovery in severe stroke: the role of motor evoked potentials in relation to early clinical assessment. Neurorehabil Neural Repair 2009;23:45.

17. Blennerhassett JM, Matyas TA, Carey LM. Impaired discrimination of surface friction contributes to pinch grip deficit after stroke. Neurorehabil Neural Repair 2007;21:263.

18. Tyson SF, Hanley M, Chillala J, Selley AB, Tallis RC. Sensory loss in hospital-admitted people with stroke: characteristics, associated factors, and relationship with function. Neurorehabil Neural Repair 2008:22:166.

19. Oliveira R, Cacho EWA, Borges G. Post-stroke motor and functional evaluations. Arq Neuropsiquiatr 2006;64:731-735.

20. Maki T, Quagliato EMAB, Cacho EWA, et al. Estudo de confiabilidade da aplicação da escala de Fugl-Meyer no Brasil. Rev Bras Fisioter São Carlos 2006;10:177-183.

21. Lima DHF, Queiroz AP, Salvo G, Yoneyama SM, Oberg TD, Lima NMFV. Versão Brasileira da Avaliação Sensorial de Nottingham: validade, concordância e confiabilidade. Rev Bras Fisioter 2010;14:166-174.

22. Valach L, Signer S, Hartmeier A, Hofer K, Steck GC. Chedoke-McMaster stroke assessment and modified Barthel Index self-assessment in patients with vascular brain damage. Int J Rehab Res 2003;26:93-99.

23. Welmer AK, Holmqvist LW, Sommerfeld DK. Limited fine hand use after stroke and its association with other disabilities. J Rehabil Med 2008; 40:603-608.

24. Julkunen $\mathrm{L}$, Tenovuo $\mathrm{O}$, Jääskeläinen $\mathrm{SK}$, Hämäläinen $\mathrm{H}$. Recovery of somatosensory deficits in acute stroke. Acta Neurol Scand 2005;111: 366-372.

25. Wagner JM, Lang CE, Sahrmann SA, Edwards DF, Dromerick AW. Sensorimotor impairments and reaching performance in subjects with poststroke hemiparesis during the first few months of recovery. Physical Therapy 2007; 87:751-765.

26. Gauthier L, Dehaut F, Joanette $Y$. The bells test: a quantitative and qualitative test for visual neglect. Internat J Neuropsychol 1989:11:49-54.

27. Michaelsen SM, Dannenbaum R, Levin MF. Task-specific training with trunk restraint on arm recovery in stroke. Stroke 2006:37:186-192.

28. Fleiss JL. Statistical methods for rates and proportions. 2nd ed. New York: John Wiley \& Sons, 199. 